\title{
Studies on Rubber (Hevea brasiliensis) Trees Exist Plant Type after Planting and Available Tapping Tree of Rubber Plantation in China
}

\author{
Dongling Qi, Jiannan Zhou, Guishui Xie, Zhixiang $\mathbf{W u}^{*}$ \\ Rubber Research Institute, Chinese Academy of Tropical Agricultural Sciences/Outdoor Key Station of \\ Agriculture Ministry for Observing and Investigating Tropical Agricultural Resources and Ecologic \\ Environment, Danzhou, China \\ Email: ${ }^{*}$ zhixiangwu@21cn.com
}

Received 14 July 2014; revised 18 August 2014; accepted 6 September 2014

Copyright (C) 2014 by authors and Scientific Research Publishing Inc.

This work is licensed under the Creative Commons Attribution International License (CC BY). http://creativecommons.org/licenses/by/4.0/

(c) (i) Open Access

\begin{abstract}
Existing plant types of rubber tree after planting and available tapping tree were investigated, and there were about 28 rubber plantations with different tapping years of 8 varieties "CATAS7-33-97", “CATAS8-79”, “CATAS7-20-59”, “PR107", “RRIM600”, “GT1”, "INA873”, “93-114” in South China. The results showed that there were six kinds of existing plant types of rubber tree after planting of rubber plantations, which were available tapping trees, wind damaged trees, cold damaged trees, tapping panel dryness trees, absent trees and weak trees, respectively. These data investigated also showed rubber trees under available tapping, stoppage due to tapping panel dryness, absence,

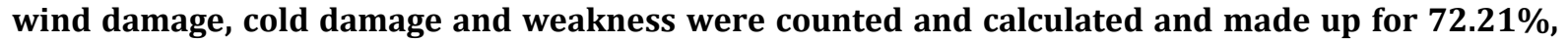
$14.75 \%, 5.61 \%, 3.86 \%, 2.68 \%$ and $1.89 \%$. Tapping panel dryness trees, wind damage and absent trees are major factors for the loss of tapping rubber trees in the rubber plantations. Of these investigated varieties, available tapping trees per 100 trees of rubber plantation of "PR107" at the $1^{\text {st }}, 12^{\text {th }}, 14^{\text {th }}, 16^{\text {th }}, 20^{\text {th }}, 24^{\text {th }}$ tapping year were $96,67,70,75,66,46$ trees in Hainan planting zone, respectively. Available tapping trees per 100 trees of rubber plantation of "RRIM600" at the $9^{\text {th }}$, $15^{\text {th }}, 2^{\text {th }}, 22^{\text {nd }}$ tapping year were 88, 62, 55, 36 trees in Yunnan planting zone, respectively. Available tapping trees per 100 trees of rubber plantation of "93-114" at the $10^{\text {th }}, 19^{\text {th }}$, tapping year were 94, 62 trees in Guangdong planting zone. These results showed that available tapping trees of rubber plantation decreased with increasing tapping age under different planting zones in China.
\end{abstract}

\section{Keywords}

Rubber Tree (Hevea brasiliensis), Exist Plant Type, Available Tapping Tree, Rubber Plantations, Different Tapping Years, China

\footnotetext{
${ }^{*}$ Corresponding author.
}

How to cite this paper: Qi, D.L., Zhou, J.N., Xie, G.S. and Wu, Z.X. (2014) Studies on Rubber (Hevea brasiliensis) Trees Exist Plant Type after Planting and Available Tapping Tree of Rubber Plantation in China. American Journal of Plant Sciences, 5, 3017-3021. http://dx.doi.org/10.4236/ajps.2014.520318 


\section{Introduction}

It is a decisive yield factor to the available tapping trees in the specific rubber land on dry rubber production. Through grasping the situation of how many available tapping trees are in the rubber land, the enterprisers and growers can estimate the production capability. Then they can make the yield plan each year and the trees renewal in time. They also can establish tapping strategy and put investment reasonably for rubber plantation. There was a very significant positive correlation between dry rubber yield and the available tapping trees for rubber plantations of variety RRIM600 in the rubber tract of Xishuangbanna [1]. Some studies showed that high dry rubber yield of rubber plantations was often attributed to higher available tapping trees [2] [3]. The low available tapping trees or the low number of tapping trees of rubber plantation was one of the reasons for low yield in the rubber plantations of Hainan State Farms [4]. In addition, the available tapping trees of rubber plantations also were one of the main factors affecting rubber production efficiency in Hainan State Farms [5]. Some researchers analyzed that severe cold injury was the main reason for low number of mature trees, and that improving number of mature trees in rubber plantation helps to achieve sustainable development of the rubber plantations [6]. Some factors such as plant density of rubber plantation [7], human behavior and its decisionmaking errors [8], strong typhoon [9] affected the growth of the rubber trees in South China. The rubber plantations yielded 1200 kilogram of dry rubber by average in China, which is quite low as compared to other natural rubber producing countries in the south-east Asia [10]. There is still a lack of objective and comprehensive understanding of the problem of low dry rubber yield for rubber plantations in China. It will help solve the problem through analysis of existing plant types of rubber tree after planting and available tapping tree of rubber plantations. This paper preliminarily studied existing plant types of rubber tree after planting and available tapping tree for rubber plantations in Hainan, Yunnan and Guangdong rubber planting zone.

\section{Material and Methods}

Rubber tree varieties “CATAS7-33-97”, “CATAS8-79”, “CATAS7-20-59”, “PR107”, “RRIM600”, “GT1”, “INA873”, “93-114”, about 28 rubber plantations with different tapping years were investigated in the major three rubber planting zone in South China, Hainan, Yunnan and Guangdong provinces during the research survey in 2014. The survey was focused on exist plant types of rubber tree after planting and available tapping tree, and 100 trees would be selected from each rubber plantation investigated. Plant and row spacing ranged from $2.5 \mathrm{~m}$ to $3 \mathrm{~m}$ and from $6 \mathrm{~m}$ to $7 \mathrm{~m}$, respectively in the rubber planting areas in Hainan and Guangdong provinces, and from $2.5 \mathrm{~m}$ to $3 \mathrm{~m}$ and $9 \mathrm{~m}$ to $7.5 \mathrm{~m}$, respectively in the rubber planting area in Yunnan province. The rubber cultural practices and latex harvest technology for the rubber plantations selected followed "Technical Regulations for Cultivation of Rubber Tree” which was issued and implemented by the People's Republic of China [11].

\section{Statistical Analyses}

All statistical data were analyzed using Microsoft Excel and SAS statistical analysis software. Survey data were used for data analysis using the following method:

Percent tapping tree $(\%)=($ Number of tapping tree/Total number of rubber tree investigated $) \times 100$;

Percent wind damaged tree $(\%)=($ Number of wind damaged tree/Total number of rubber tree investigated $) \times$ 100 ;

Percent cold damaged tree $(\%)=($ Number of cold damaged tree/Total number of rubber tree investigated $) \times$ 100 ;

Percent tapping panel dryness tree $(\%)=$ (Number of tapping panel dryness tree/Total number of rubber tree investigated) $\times 100$;

Percent absent tree $(\%)=($ Number of absent tree/Total number of rubber tree investigated $) \times 100$;

Percent weak tree $(\%)=($ Number of weak tree/Total number of rubber tree investigated $) \times 100$.

\section{Results and Discussion}

This investigation showed that there were six kinds of existing plant types of rubber tree after planting of rubber plantations (Table 1), which were available tapping trees, wind damaged trees, cold damaged trees, tapping panel dryness trees, absent trees and weak trees, respectively. From the point of view of all varieties survey, 
Table 1. Analysis of available tapping trees under different growing environments in China.

\begin{tabular}{|c|c|c|c|c|c|c|c|c|c|}
\hline Rubber tract & Variety & $\begin{array}{c}\text { Tapping } \\
\text { years }\end{array}$ & $\begin{array}{c}\text { Sample } \\
\text { trees }\end{array}$ & $\begin{array}{c}\text { Available } \\
\text { tapping } \\
\text { trees }\end{array}$ & $\begin{array}{l}\text { Wind } \\
\text { damaged } \\
\text { trees }\end{array}$ & $\begin{array}{l}\text { Cold } \\
\text { damaged } \\
\text { trees }\end{array}$ & $\begin{array}{c}\text { Tapping } \\
\text { panel } \\
\text { dryness trees }\end{array}$ & $\begin{array}{l}\text { Absent } \\
\text { trees }\end{array}$ & $\begin{array}{c}\text { Weak tree } \\
\text { trees }\end{array}$ \\
\hline \multirow[t]{14}{*}{ Hainan zone } & \multirow[t]{3}{*}{ CATAS7-33-97 } & 1 & 100 & 96 & 0 & 0 & 0 & 1 & 3 \\
\hline & & 5 & 100 & 85 & 7 & 0 & 3 & 3 & 2 \\
\hline & & 10 & 100 & 71 & 5 & 0 & 17 & 5 & 2 \\
\hline & \multirow[t]{2}{*}{ CATAS8-79 } & 1 & 100 & 90 & 5 & 0 & 0 & 0 & 5 \\
\hline & & 4 & 100 & 73 & 13 & 0 & 14 & 0 & 0 \\
\hline & CATAS7-20-59 & 4 & 100 & 92 & 0 & 0 & 6 & 0 & 2 \\
\hline & \multirow[t]{6}{*}{ PR107 } & 1 & 100 & 96 & 0 & 0 & 0 & 1 & 3 \\
\hline & & 12 & 100 & 67 & 7 & 7 & 5 & 12 & 2 \\
\hline & & 14 & 100 & 70 & 6 & 4 & 9 & 6 & 5 \\
\hline & & 16 & 100 & 75 & 4 & 2 & 9 & 6 & 4 \\
\hline & & 20 & 100 & 66 & 6 & 8 & 13 & 5 & 2 \\
\hline & & 24 & 100 & 46 & 3 & 15 & 21 & 11 & 4 \\
\hline & \multirow[t]{2}{*}{ RRIM600 } & 16 & 100 & 64 & 6 & 8 & 8 & 12 & 2 \\
\hline & & 20 & 100 & 52 & 5 & 7 & 17 & 15 & 4 \\
\hline \multirow[t]{9}{*}{ Yunnan zone } & \multirow[t]{2}{*}{ PR107 } & 5 & 100 & 92 & 0 & 0 & 1 & 1 & 6 \\
\hline & & 39 & 100 & 52 & 3 & 7 & 38 & 0 & 0 \\
\hline & \multirow[t]{3}{*}{ GT1 } & 10 & 100 & 88 & 0 & 0 & 10 & 1 & 1 \\
\hline & & 16 & 100 & 84 & 1 & 0 & 13 & 1 & 1 \\
\hline & & 22 & 100 & 52 & 2 & 0 & 46 & 0 & 0 \\
\hline & \multirow[t]{4}{*}{ RRIM600 } & 9 & 100 & 88 & 1 & 9 & 0 & 0 & 2 \\
\hline & & 15 & 100 & 62 & 3 & 0 & 27 & 7 & 1 \\
\hline & & 20 & 100 & 55 & 0 & 0 & 44 & 1 & 0 \\
\hline & & 22 & 100 & 36 & 0 & 0 & 62 & 0 & 2 \\
\hline \multirow[t]{5}{*}{ Guangdong zone } & PR107 & 20 & 100 & 59 & 5 & 1 & 7 & 28 & 0 \\
\hline & GT1 & 29 & 100 & 54 & 12 & 0 & 9 & 25 & 0 \\
\hline & $93-114$ & 10 & 100 & 94 & 0 & 2 & 4 & 0 & 0 \\
\hline & $93-114$ & 19 & 100 & 62 & 3 & 5 & 27 & 3 & 0 \\
\hline & IAN873 & 15 & 100 & 73 & 11 & 0 & 3 & 13 & 0 \\
\hline
\end{tabular}

rubber trees under available tapping, stoppage due to tapping panel dryness, absence, wind and cold damage and weakness were counted and calculated and made up for $72.21 \%, 14.75 \%, 5.61 \%, 3.86 \%, 2.68 \%$ and $1.89 \%$ of the total number of trees of the planting density, respectively (Figure 1). The above findings showed tapping panel dryness, absence and wind damage are major factors for the loss of tapping rubber trees in the rubber plantations.

This investigation showed that rubber available tapping trees of rubber plantations presented downward trend with increasing tapping age (Table 1). In Hainan planting zone, available tapping trees per 100 trees of rubber plantation of "PR107" at the 1st, 12th, 14th, 16th, 20th, 24th tapping year was 96, 67, 70, 75, 66, 46 trees respectively, and available tapping trees per 100 trees of CATAS 7-33-97 at the tapping year 1st, 5th and 10th was 96, 85 and 71 trees, respectively. In Yunnan planting zone, available tapping trees of rubber plantation per 100 trees of "RRIM600" at the 9th, 15th, 20th, 22nd tapping year was 88, 62, 55, 36 trees, respectively, and available tapping trees per 100 trees of rubber plantation of "GT1" at the 10th, 16th, 22nd tapping year was 88, 84, 22 trees. In Guangdong planting zone, available tapping trees per 100 trees of rubber plantation of "93-114" at the 10th, 19th tapping year was 94, 62 trees, respectively. These results also showed that available tapping trees of rubber 


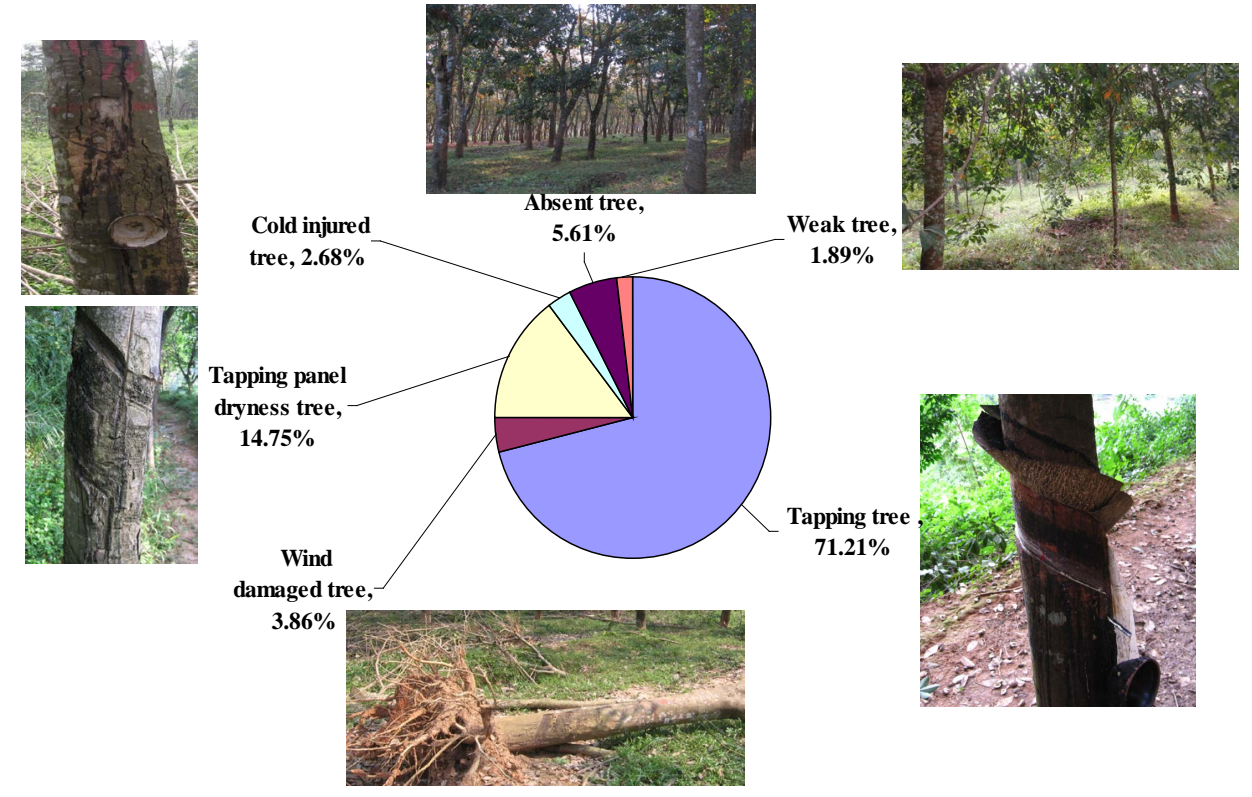

Figure 1. Type and ratio of rubber plant standing under different growing environments in China.

plantation decreased with increasing tapping age under different planting zone of Hainan, Yunnan, Guangdong in China, and available tapping tree densities in rubber plantations of different varieties showed a similar decline trend with the increase of tapping years.

This result showed existing plant types of rubber tree after planting of rubber plantations were various. That is to say, there were numerous factors affecting the available tapping trees in rubber plantations: poor cultural practices for immature trees, damages due to cold, drought and wind, as well as root disease, etc. A clear understanding of these factors will help to take targeted measures for rubber cultivation and plantation management.

Available tapping trees and individual yield significantly declined with a rise in elevation in Vietnam, and as available tapping trees increased yield per tree declined whereas latex productivity rose [12]. High-density planting has been proven to be effective in minimizing wind damage. Bole growth and yield were strongly influenced by planting density, and the optimum planting density was determined at 650 trees/ha in south western Côte d'Ivoire, but available tapping tree did not vary much with the density of planting [13]. Bark thickness and number of latex vessel rings of rubber trees declined as the planting density increased from 400 to 920 trees per ha, and yield per tree per tapping decreased, but yield per ha per tapping and net present value increased with the increase in planting density [14]. Smallholders generated the highest income and profits from their land only when their smallholdings maintained at 401 - 500 effective tapping trees per ha at the tapping ages of 10 - 15 years old, and the initial planting density of the smallholdings should be $600-750$ trees per ha to ensure this number of available tapping trees per ha since rubber trees had a mortality rate of $10 \%$ after planted, and in fact only about $75 \%$ of the plants were available tapping [15]. The percentage of infected and stubble trees was getting rise with the increase of rubber tree tapping years, and available tapping trees after 7 years of tapping declined with the increase of rubber tree tapping years [16].

Rubber tree generally has an economic life cycle of over 30 years, and is cultivated and managed as a longterm crop once planted. Hence, good management of each rubber tree in rubber plantations at the early stage is an important factor for high available tapping trees when the rubber tree enters into the latex harvest period. Wind and cold damages are common factors reducing available tapping trees of rubber plantations. The wind and cold often threaten the rubber production in the main rubber producing areas in China: Hainan, Yunnan and Guangdong. Rubber producing areas are zoned based on the pathways of cold current and typhoon. Varieties of rubber trees with wind or cold tolerance are planted based on the environments and protected in different ways whenever cold current and typhoon attack the rubber plantations. It is important for rubber growers to be conscious of the importance of environmental approach to plant rubber trees in the non-traditional area.

The tapping intensity is also an important factor affecting the available tapping trees of rubber plantations. Tapping system taken should be based on the performance of rubber plantations and clones, and tapping skill 
has a very important impact on yield and TPD. Latex yield harvested from rubber plantations should be reasonably based on the growth of rubber trees. Annual check on TPD index should also be done continuously when a tapping system is introduced.

\section{Conclusion}

The results of this study indicated that there were six kinds of existing plant types of rubber tree after planting of rubber plantations in South China, which were available tapping trees, wind damaged trees, cold damaged trees, tapping panel dryness trees, absent trees and weak trees, respectively. These data investigated showed rubber trees under available tapping, stoppage due to tapping panel dryness, absence, wind damage, cold damage and weakness were counted and calculated and made up for $72.21 \%, 14.75 \%, 5.61 \%, 3.86 \%, 2.68 \%$ and $1.89 \%$. Tapping panel dryness trees, wind damage and absent trees are major factors for the loss of tapping rubber trees in the rubber plantations. These results also showed that available tapping trees of rubber plantation decreased with increasing tapping age under different planting zones in China.

\section{Acknowledgements}

The author wishes to thank production management personnel of rubber plantations of Hainan, Yunnan and Guangdong Provinces for the assistance of the investigation. Thanks are also due to Mr. Yan Zongpu and Dr. Ma Xiaowei for their guidance of our work.

\section{References}

[1] Zhu, X.D. (1995) Relationship between Yield of Rubber Tapping Trees per ha and Planting Density. Chinese Journal of Tropical Crop Science and Technology, 4, 33, 45-46.

[2] Luo, Y.H., Luo, S.Y. and Fu, H.B. (2006) Report of High Yielding Rubber Plantations in Bayi State Farm. Chinese Journal of Hainan State Farm Science and Technology, 18, 1-3.

[3] Lin, W.L. (2007) Analysis of High and Stable Yield of Rubber Plantations in Zhubijiang State Farms. Chinese Journal of Hainan State Farm Science and Technology, 19, 32-36.

[4] Huang, X.Q. (2008) Primary Analysis of Possibility and Means of Increasing Production Potential in Hainan State Farm. Chinese Journal of Tropical Agricultural Sciences, 28, 55-58, 65.

[5] Xu, H.P. and Fu, G.H. (2008) Hainan State Farms Natural Rubber Production of Technical Efficiency AnalysisBased on Stochastic Frontier Analysis Method. Chinese Rural Economy, 24, 39-45.

[6] Yang, Y.P. and Chen, W.Q. (2008) Canonical Correlation Analysis of Natural Rubber Industry of Yunnan State Farms Group and Its Sustainable Development. Chinese Journal of Tropical Agricultural Science and Technology, 31, 40-45.

[7] He, Z.G., Jiang, J.S. and Zheng, D.H. (2008) Relations between Rubber Planting Density, Planting Form and Growth, Yield Benefits. Modern Agricultural Science and Technology, 37, 5-7, 10.

[8] Yang, G.M. (2008) Effective Factors Analysis on Reducing the Number of Rubber Trees for Guangxi State Rong Guang Farms of Rubber Plantations. World Tropical Agriculture Information, 46, 25.

[9] Li, Z.Q. (2006) Impact Analysis and Countermeasures of "David” Typhoon on Rubber Production in Hainan State Farm. Chinese Society of Tropical Crop Natural Rubber Professional Committee Symposium, Nanjing, 12-15 June 2006, 97-106.

[10] Mo, Y.Y. and Huang, H.S. (2009) Changes in Trade Policy and Development Ideas of Natural Rubber Industry. Chinese Journal of Tropical Agriculture in China, 6, 8-11.

[11] Ministry of Agriculture, China (2006) Technical Regulations for Cultivation of Rubber Tree. NY/T 221-2006.

[12] Binh, T.N. (2013) Large-Scale Altitudinal Gradient of Natural Rubber Production in Vietnam. Industrial Crops and Products, 41, 31-40. http://dx.doi.org/10.1016/j.indcrop.2012.04.006

[13] Obouayeba, S., Dian, K., Boko, A.M.C. and Gnagne, Y.M. (2005) Effect of Planting Density on Growth and Yield Productivity of Hevea brasiliensis Muell. Arg. Clone PB 235. Journal of Rubber Research, 8, 57-270.

[14] Kodikara, P.B. and Weeralal, J.L.K. (1995) Effect of Planting Density on Growth, Yield Related Factors and Profitability of Rubber (Hevea brasiliensis Muell. Arg.). Journal of the Rubber Research Institute of Sri Lanka, 76, 55-71.

[15] Abdullah, B.S. (1979) Planting Density of Smallholdings. World Tropical Agriculture Information, 23, 18-22.

[16] Wang, Q.B., Mei, Z.Q. and Liu, Z.L. (2013) Investigation and Thinking of Hevea brasiliensis Clones under Treatment of New Tapping System. Chinese Journal of Tropical Agricultural Science and Technology, 36, 11-15. 
Scientific Research Publishing (SCIRP) is one of the largest Open Access journal publishers. It is currently publishing more than 200 open access, online, peer-reviewed journals covering a wide range of academic disciplines. SCIRP serves the worldwide academic communities and contributes to the progress and application of science with its publication.

Other selected journals from SCIRP are listed as below. Submit your manuscript to us via either submit@scirp.org or Online Submission Portal.
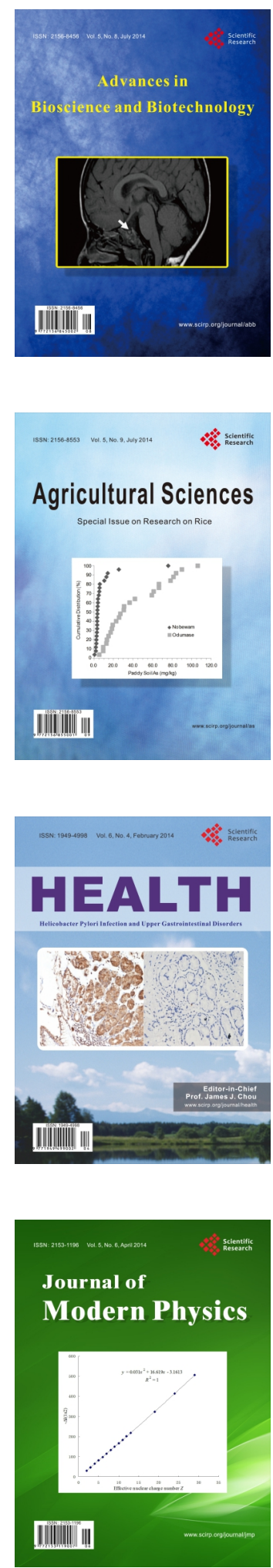
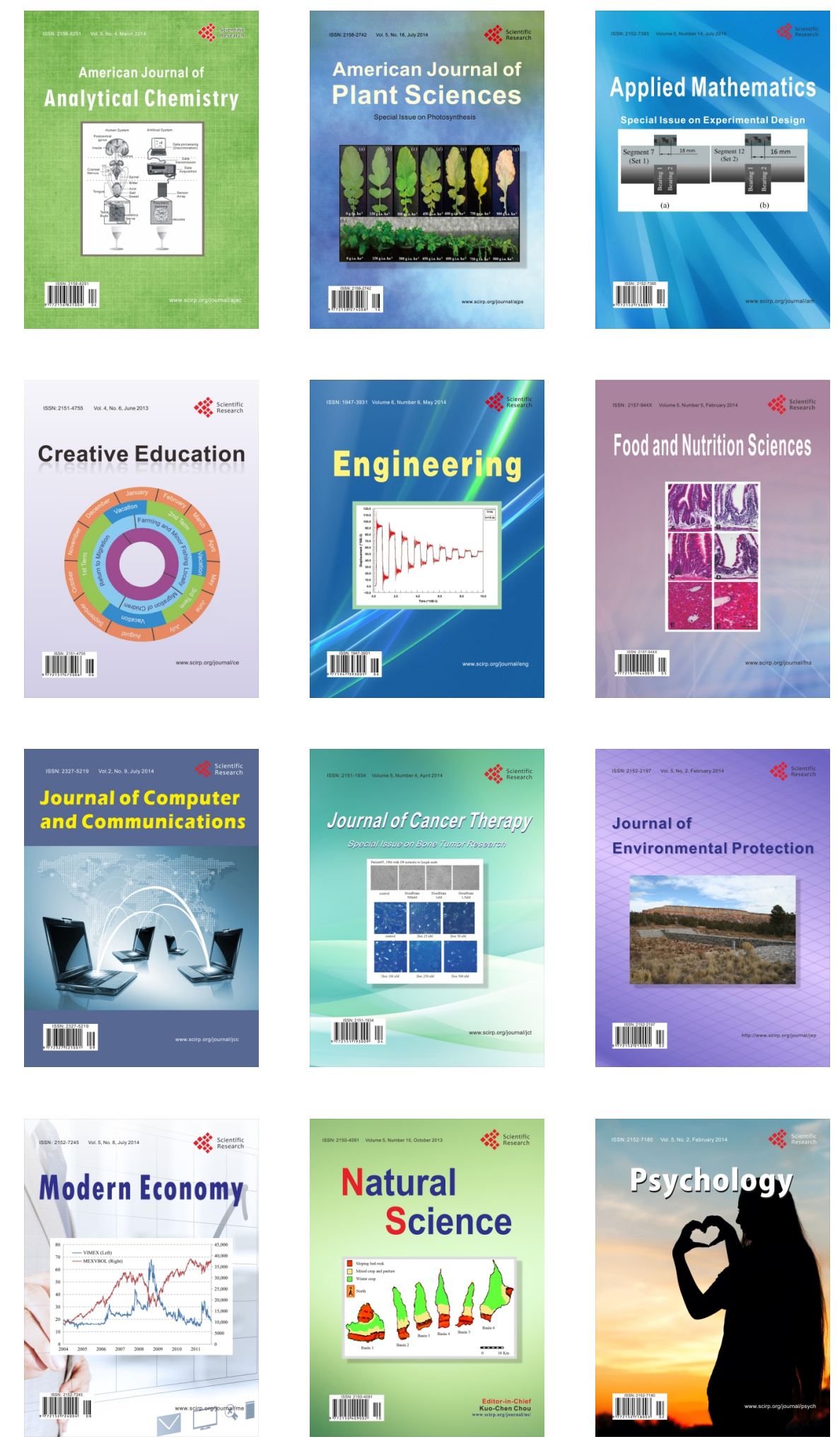